\title{
Microplate motions in the hotspot reference frame
}

\author{
Marco Cuffaro ${ }^{1}$ and Donna M. Jurdy ${ }^{2}$ \\ ${ }^{1}$ Dipartimento di Scienze della Terra, Università degli Studi di Roma "La Sapienza", P.le A. Moro 5, 00185 Rome, Italy; ${ }^{2}$ Department of \\ Geological Sciences, Northwestern University, 1850 Campus Drive, Evanston, IL 60208, USA
}

\begin{abstract}
We have computed motions of the major plates (seven large plates and seven medium-sized plates) and 38 microplates relative to the hotspot reference frame, and present velocities of these 52 plates. Moreover, using updated plate boundaries for the present, we have computed new geometrical factors for plates and microplates, useful for kinematic calculations and to obtain the net-rotation of the lithosphere and plate velocities in the mean-lithosphere reference frame. Instead of a continuum or gradational distribution of the plates by size, the plates clearly partition into three groups each having their own characteristics. For the seven large
\end{abstract}

plates, rotation poles generally lie in high latitudes; the seven medium-sized plates have rotation poles in a restricted equatorial area; the 38 small plates show the greatest scatter. Moreover subsets of the 52 plates reveal differing fractal behaviour: the large, middle and small groupings each have a characteristic fractal dimension, suggestive of microplate clustering. The highest angular velocities occur for some of the smallest plates, with the location of their rotation poles closeby.

Terra Nova, 18, 276-281, 2006

\section{Introduction}

In this paper, we compute absolute motions that describe the motion of plates and microplates with respect to the mesosphere. In plate kinematic and dynamic analyses, two different absolute reference frames have been utilized: fixed-hotspots and meanlithosphere. The first, the 'hotspot reference frame', is based on the assumption that individual hotspots are fixed relative to the mesosphere and to each other (Morgan, 1972; Wilson, 1973). Under this hypothesis, a seamount chain such as the Hawaiian-Emperor describes the motion of the overlying Pacific plate relative to the Hawaiian hotspot assumed stationary. The second frame, for the no-net-rotation condition (NNR) (Solomon and Sleep, 1974), rests upon the assumption that lithosphere and asthenosphere are uniformly coupled. Because both absolute reference frames are referred to the mesosphere, any difference between the frames would be interpreted as a net-rotation of the lithosphere with respect to the mesosphere (Forsyth and Uyeda, 1975).

Here, we choose the hotspot reference frame (Gripp and Gordon, 2002) to describe 52 plate and micro-

Correspondence: Marco Cuffaro, Dipartimento di Scienze della Terra, Università degli Studi di Roma "La Sapienza", P. le A. Moro 5, 00185 Rome, Italy. Tel.: 3906 4991 4156; fax: 39064454 729; e-mail: marco.cuffaro@uniromal.it plate motions. In addition, we compute plate and microplate velocities in the corresponding NNR frame.

\section{Methods and results}

Gripp and Gordon (2002) defined a hotspot reference frame using 11 segment trends and two volcanic propagation rates, obtaining absolute plate motions for an c. 5.8 Myr time interval. First, they estimated segment trends and volcanic propagation rates by least-square methods and then, in this frame, computed a set of angular velocities consistent with the relative plate motions model NUVEL-1A (DeMets et al., 1990, 1994). In their study, only the Hawaiian and Society tracks were used to position the Pacific plate, giving a Pacific angular velocity of $1.0613^{\circ} \mathrm{Myr}^{-1}$ about a pole located at $61.467^{\circ} \mathrm{S}, 90.326^{\circ} \mathrm{E}$. Adding the Pacific plate angular velocity to the relative model NUVEL-1A (DeMets et al., 1990, 1994) results in the present-day velocities in the hotspot reference frame.

Using these methods, we computed plate and microplate motions in the hotspot frame, using the PB2002 database (Bird, 2003) for 52 plates (Table 1 and Fig. 1). The PB2002 model also gives 52 new plate boundaries in digital form, and relative plate and microplate motions are referred to an arbitrary Pacific plate fixed, some coming from the literature, others newly interpreted. In that model, the velocities of the 10 largest plates,
Africa (AF), Antarctica (AN), Arabia (AR), Australia (AU), Cocos (CO), Eurasia (EU), India (IN), Nazca (NZ), North America (NA) and South America (SA) come from the NUVEL-1A (DeMets et al., 1990, 1994); therefore for these plates we exactly reproduced the HS3-NUVEL1A results (Gripp and Gordon, 2002) (Table 1). Using the other relative motions collected and proposed by Bird (2003, his Table 1), we obtain new Euler vectors relative to the hotspots for the remaining 42 plates and microplates (Table 1).

Although the covariance matrix of the Pacific plate is computed by Gripp and Gordon (2002), the uncertainties of the angular velocities for plates and microplates in the hotspots are not presented in this paper, because the errors of relative plate motions of the PB2002 model (Bird, 2003) are not reported. Using errors of $50 \mathrm{~km}$ for the location of individual hotspots, Jurdy (1990) calculated an uncertainty of $1.1^{\circ}$ for the hotspot reference frame. Thus, in view of that study and also the standard deviations of the HS3-NUVEL1A model (Gripp and Gordon, 2002) for plate Euler vectors, we would obtain rather large uncertainties for microplate angular velocities.

Figure 1 shows current plate and microplate linear velocities relative to the hotspots. Most of the microplates are on the Pacific-Australia boundary (Fig. 1a,b). Their motions are principally $\mathrm{W}-\mathrm{NW}$-ward directed with different velocities, except for 
Table 1 Microplate and plate geometrical factors and angular velocities relative to the hotspots. Plates are sorted by area

\begin{tabular}{|c|c|c|c|c|c|c|c|c|c|c|c|}
\hline \multirow[b]{2}{*}{ Plate } & \multirow[b]{2}{*}{ Definition } & \multirow[b]{2}{*}{ Area* } & \multicolumn{3}{|c|}{ Angular velocity } & \multicolumn{6}{|c|}{ Geometrical factors* } \\
\hline & & & ${ }^{\circ} \mathrm{N}$ & ${ }^{\circ} \mathrm{E}$ & ${ }^{\circ} \mathrm{Myr}^{-1}$ & $I_{x x}$ & $I_{\mathrm{yy}}$ & $I_{\mathrm{zz}}$ & $I_{x y}$ & $I_{x z}$ & $l_{\mathrm{yz}}$ \\
\hline PA & Pacific & 2.5768 & -61.467 & 90.326 & 1.0613 & 1.1757 & 1.9612 & 2.0168 & -0.4295 & 0.0774 & -0.0574 \\
\hline AF & Africa & 1.4407 & -43.386 & 21.136 & 0.1987 & 0.3726 & 1.3012 & 1.2075 & -0.0513 & -0.0054 & 0.0442 \\
\hline AN & Antarctica & 1.4326 & -47.339 & 74.514 & 0.2024 & 1.3267 & 1.1747 & 0.3638 & -0.0510 & 0.0525 & 0.0813 \\
\hline NA & North America & 1.3657 & -74.705 & 13.400 & 0.3835 & 1.2286 & 0.9416 & 0.5612 & 0.0662 & -0.0036 & 0.3963 \\
\hline EU & Eurasia & 1.1963 & -61.901 & 73.474 & 0.2047 & 1.0059 & 0.8948 & 0.4919 & -0.0356 & -0.2132 & -0.3103 \\
\hline$A U$ & Australia & 1.1329 & -0.091 & 44.482 & 0.7467 & 0.8003 & 0.5884 & 0.8772 & 0.2032 & -0.2132 & 0.2881 \\
\hline SA & South America & 1.0305 & -70.583 & 80.401 & 0.4358 & 0.6255 & 0.6092 & 0.8262 & 0.3403 & 0.1914 & -0.1716 \\
\hline SO & Somalia & 0.4719 & -53.406 & 4.344 & 0.1192 & 0.2842 & 0.2349 & 0.4248 & -0.1982 & 0.0608 & 0.0655 \\
\hline NZ & Nazca & 0.3967 & 35.879 & -90.913 & 0.3231 & 0.3854 & 0.0684 & 0.3396 & -0.0126 & -0.0030 & -0.1134 \\
\hline IN & India & 0.3064 & 3.069 & 26.467 & 0.5211 & 0.2863 & 0.0423 & 0.2841 & -0.0570 & -0.0131 & -0.0605 \\
\hline SU & Sunda & 0.2197 & -6.772 & -26.816 & 0.2037 & 0.1888 & 0.0363 & 0.2142 & 0.0691 & 0.0065 & -0.0168 \\
\hline PS & Philippine Sea & 0.1341 & -52.742 & -16.819 & 1.1978 & 0.0777 & 0.0713 & 0.1192 & 0.0583 & 0.0266 & -0.0276 \\
\hline AM & Amur & 0.1306 & -70.123 & 12.836 & 0.1553 & 0.1082 & 0.0895 & 0.0636 & 0.0287 & 0.0363 & -0.0513 \\
\hline AR & Arabia & 0.1208 & 2.951 & 23.175 & 0.5083 & 0.0742 & 0.0668 & 0.1006 & -0.0488 & -0.0296 & -0.0310 \\
\hline OK & Okhotsk & 0.0748 & -74.713 & 28.719 & 0.2454 & 0.0534 & 0.0664 & 0.0298 & 0.0130 & 0.0303 & -0.0179 \\
\hline CA & Caribbean & 0.0731 & -64.494 & -6.969 & 0.2196 & 0.0660 & 0.0120 & 0.0681 & 0.0180 & -0.0052 & 0.0171 \\
\hline $\mathrm{CO}$ & Cocos & 0.0722 & 13.171 & -116.997 & 1.1621 & 0.0711 & 0.0030 & 0.0704 & -0.0055 & 0.0011 & 0.0101 \\
\hline YA & Yangtze & 0.0543 & 0.005 & 108.306 & 0.1617 & 0.0457 & 0.0200 & 0.0429 & 0.0166 & 0.0096 & -0.0195 \\
\hline SC & Scotia & 0.0419 & -77.268 & 51.747 & 0.4512 & 0.0367 & 0.0345 & 0.0126 & 0.0057 & 0.0120 & -0.0145 \\
\hline $\mathrm{CL}$ & Caroline & 0.0377 & -67.826 & 54.057 & 0.9482 & 0.0153 & 0.0225 & 0.0375 & 0.0182 & 0.0016 & -0.0013 \\
\hline ND & North Andes & 0.0239 & -66.874 & 88.610 & 0.3629 & 0.0224 & 0.0020 & 0.0235 & 0.0058 & -0.0007 & 0.0025 \\
\hline AP & Altiplano & 0.0205 & -57.402 & -65.177 & 0.5044 & 0.0182 & 0.0042 & 0.0187 & 0.0061 & 0.0021 & -0.0054 \\
\hline BS & Banda Sea & 0.0171 & -7.931 & 116.220 & 2.5106 & 0.0113 & 0.0060 & 0.0170 & 0.0088 & -0.0009 & 0.0012 \\
\hline $\mathrm{NH}$ & New Hebrides & 0.0158 & -7.206 & -0.892 & 2.5912 & 0.0019 & 0.0154 & 0.0143 & 0.0023 & -0.0045 & 0.0008 \\
\hline AT & Anatolia & 0.0142 & 21.319 & 35.874 & 1.1875 & 0.0080 & 0.0116 & 0.0088 & -0.0040 & -0.0058 & -0.0037 \\
\hline BH & Birds Head & 0.0130 & -47.199 & 89.453 & 1.181 & 0.0072 & 0.0058 & 0.0129 & 0.0064 & -0.0002 & 0.0002 \\
\hline BU & Burna & 0.0127 & -13.616 & -72.199 & 2.2091 & 0.0126 & 0.0004 & 0.0123 & 0.0009 & 0.0001 & -0.0019 \\
\hline KE & Kermadec & 0.0124 & 30.673 & 11.939 & 2.2652 & 0.0038 & 0.0124 & 0.0087 & -0.0001 & -0.0056 & 0.0000 \\
\hline WL & Woodlark & 0.0112 & -10.765 & 121.708 & 1.8733 & 0.0035 & 0.0078 & 0.0110 & 0.0050 & -0.0011 & 0.0007 \\
\hline MA & Mariana & 0.0104 & -2.188 & 129.087 & 1.2627 & 0.0040 & 0.0074 & 0.0094 & 0.0044 & 0.0025 & -0.0017 \\
\hline MS & Molucca Sea & 0.0103 & -2.378 & -52.330 & 3.582 & 0.0072 & 0.0031 & 0.0103 & 0.0047 & -0.0001 & 0.0002 \\
\hline NB & North Bismarck & 0.0096 & -51.303 & 109.171 & 1.2242 & 0.0026 & 0.0070 & 0.0095 & 0.0042 & -0.0004 & 0.0002 \\
\hline TI & Timor & 0.0087 & -12.605 & 106.497 & 1.9539 & 0.0058 & 0.0031 & 0.0085 & 0.0040 & -0.0008 & 0.0011 \\
\hline ON & Okinawa & 0.0080 & 28.131 & 132.145 & 2.5439 & 0.0056 & 0.0041 & 0.0063 & 0.0030 & 0.0020 & -0.0026 \\
\hline AS & Aegean Sea & 0.0080 & -42.838 & 89.030 & 0.4515 & 0.0038 & 0.0070 & 0.0051 & -0.0019 & -0.0034 & -0.0016 \\
\hline SB & South Bismarck & 0.0077 & 4.427 & -29.965 & 8.0525 & 0.0021 & 0.0056 & 0.0076 & 0.0033 & -0.0006 & 0.0003 \\
\hline PM & Panama & 0.0068 & -82.553 & -101.535 & 0.1998 & 0.0066 & 0.0003 & 0.0066 & 0.0001 & -0.0002 & 0.0010 \\
\hline$J F$ & Juan De Fuca & 0.0064 & -39.368 & 61.745 & 1.0117 & 0.0052 & 0.0044 & 0.0031 & -0.0015 & 0.0019 & 0.0025 \\
\hline TO & Tonga & 0.0063 & 23.449 & 5.813 & 8.9185 & 0.0008 & 0.0062 & 0.0055 & -0.0005 & -0.0019 & -0.0002 \\
\hline BR & Balmoral Reef & 0.0049 & -64.237 & 97.967 & 0.8758 & 0.0004 & 0.0048 & 0.0045 & 0.0003 & -0.0012 & 0.0001 \\
\hline SW & Sandwich & 0.0046 & -46.255 & -24.275 & 2.1207 & 0.0035 & 0.0043 & 0.0013 & 0.0005 & 0.0018 & -0.0009 \\
\hline EA & Easter & 0.0042 & 23.065 & 67.522 & 11.4154 & 0.0036 & 0.0013 & 0.0034 & -0.0013 & -0.0006 & -0.0014 \\
\hline CR & Caonway Reef & 0.0036 & -25.548 & 167.064 & 3.9894 & 0.0004 & 0.0035 & 0.0032 & 0.0003 & -0.0011 & 0.0001 \\
\hline SS & Solomon Sea & 0.0032 & -13.765 & 123.523 & 1.8422 & 0.0007 & 0.0025 & 0.0031 & 0.0013 & -0.0004 & 0.0002 \\
\hline $\mathrm{NI}$ & Niuafo'ou & 0.0031 & -9.705 & 182.111 & 3.222 & 0.0003 & 0.0030 & 0.0028 & -0.0002 & -0.0008 & -0.0001 \\
\hline MO & Maoke & 0.0029 & -9.667 & 84.933 & 0.9678 & 0.0013 & 0.0016 & 0.0028 & 0.0014 & -0.0001 & 0.0001 \\
\hline RI & Riviera & 0.0025 & 17.605 & -107.298 & 3.8881 & 0.0023 & 0.0005 & 0.0022 & -0.0006 & 0.0002 & 0.0008 \\
\hline$J Z$ & Juan Fernandez & 0.0024 & 33.26 & 70.701 & 22.3832 & 0.0022 & 0.0009 & 0.0017 & -0.0006 & -0.0004 & -0.0010 \\
\hline SL & Sherland & 0.0018 & -51.811 & 112.365 & 0.2151 & 0.0017 & 0.0015 & 0.0004 & 0.0002 & 0.0004 & -0.0006 \\
\hline FT & Futuna & 0.0008 & -20.476 & 175.617 & 5.1096 & 0.0001 & 0.0008 & 0.0007 & 0.0000 & -0.0002 & 0.0000 \\
\hline GP & Galapagos & 0.0003 & -0.713 & 77.892 & 5.6985 & 0.0003 & 0.0000 & 0.0004 & -0.0001 & 0.0000 & 0.0000 \\
\hline MN & Manus & 0.0002 & -4.056 & 149.967 & 51.6116 & 0.0000 & 0.0002 & 0.0002 & 0.0001 & 0.0000 & 0.0000 \\
\hline LS & Lithosphere & 12.566 & -55.319 & 69.384 & 0.4296 & 8.3777 & 8.3777 & 8.3778 & 0.0002 & -0.0002 & 0.0004 \\
\hline
\end{tabular}

*Units are in steradians.

the Niuafo'ou (NI), Kermadec (KE) and Tonga (TO) microplates (E-NEward directed) (Fig. 1b). The other small plate velocities are generally

W-NW-ward oriented except for the

Sandwich (SW) and Galapagos (GP) microplate (Fig. 1c) (SW-ward oriented). Easter Island (EA) and Jun Fernandez (JZ) show a NW-ward 


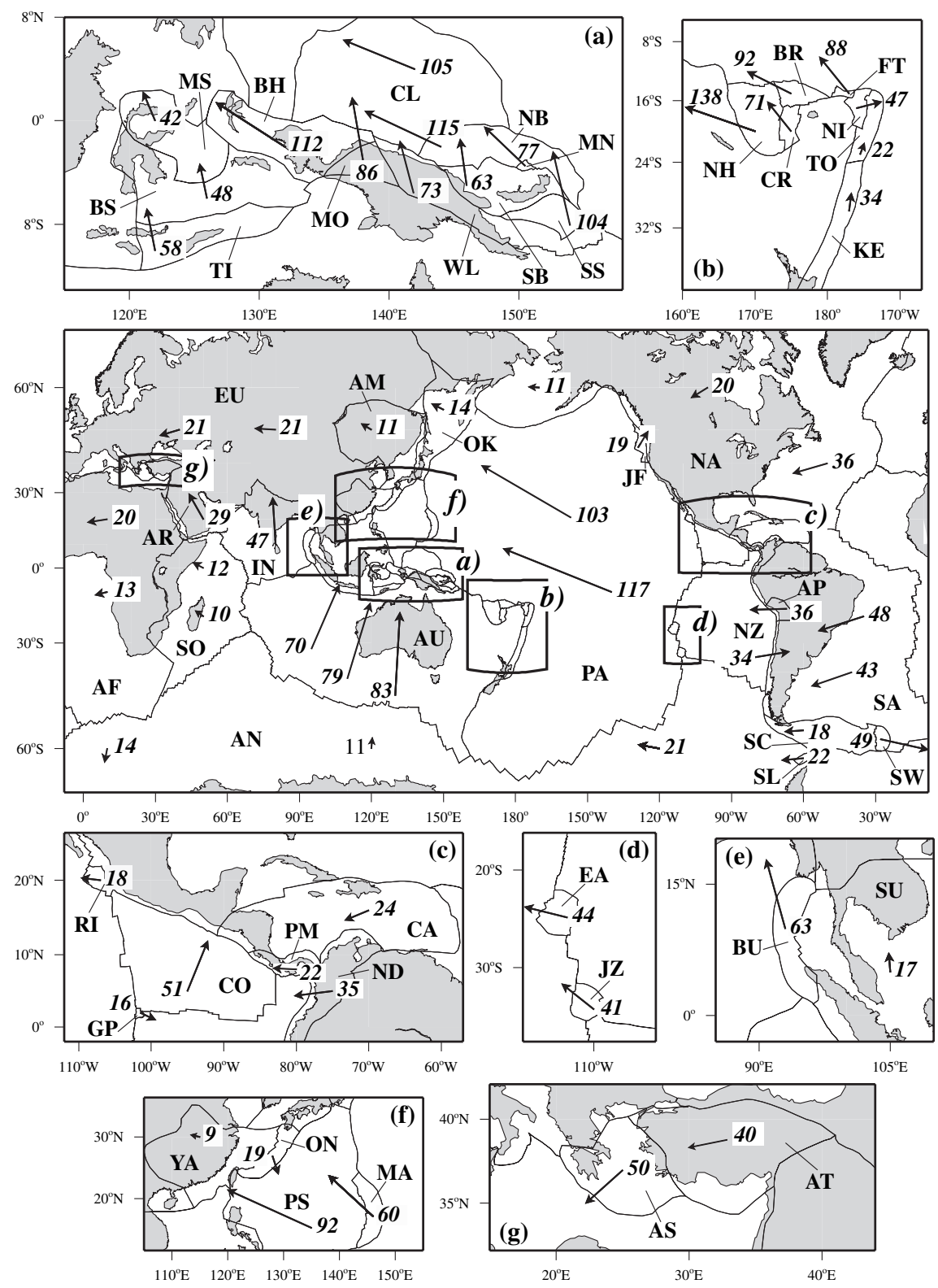

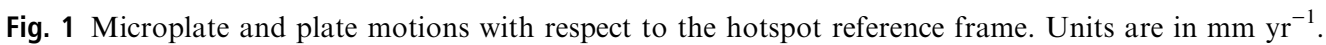

direction (Fig. 1d), whereas Burna (BU) (Fig. 1e) is mostly $\mathrm{N}$-ward directed and Okinawa (ON) (Fig. 1f) is SE-ward directed. Egean Sea (AS) and Anatolia (AT) (Fig. 1g) have instead SW-ward oriented linear velocities.

Starting with these data, we compute plate and microplate geometrical factors, useful to compute net-rotation of the lithosphere. We define the symmetric tensor $I_{p}$ (Gordon and Jurdy, 1986; Jurdy, 1990) describing plate geometry for a single plate $p$ on a unit sphere:

$$
I_{p}=\int_{S}\left[\begin{array}{ccc}
1-x^{2} & -x y & -x z \\
-x y & 1-y^{2} & -y z \\
-x z & -y z & 1-z^{2}
\end{array}\right] \mathrm{d} S
$$

where $x, y, z$ are the Cartesian coordinates of a plate $p, S$ the plate surface and $\mathrm{d} S$ is the area element. The $x-, y$ and $z$-directions are defined from the centre of the Earth to $\left(0^{\circ} \mathrm{N}, 0^{\circ} \mathrm{E}\right)$, $\left(0^{\circ} \mathrm{N}, 90^{\circ} \mathrm{E}\right)$ and $\left(90^{\circ} \mathrm{N}, 0^{\circ} \mathrm{E}\right)$, respectively. Geometrical factors of plates and microplates defined by Eq. (1) are reported in Table 1.

The net-rotation of the lithosphere concept can assume different geo- physical meanings (Lliboutry, 1974; Solomon and Sleep, 1974); it also describes the NNR framework rotation with respect to the hotspot frame (Argus and Gordon, 1991).

The net-rotation angular velocity $\omega_{\text {nr }}$ can be computed with a matrix equation:

$$
\omega_{\mathrm{nr}}=\frac{3}{8 \pi} \sum_{p=1}^{P} I_{p} \omega_{p}
$$

where $P$ is the total number of plates and microplates, $I_{p}$ is geometrical factors for plate $p$, and $\omega_{p}$ is the 
angular velocity for that plate (Table 1).

The resulting present net-rotation of the lithosphere relative to the mesosphere is described by a righthanded rotation about an Euler pole at $55.319^{\circ} \mathrm{S}, \quad 69.384^{\circ} \mathrm{E}$ and $0.4296^{\circ} \mathrm{Myr}^{-1}$.

To obtain the angular velocity of a single plate $p$ in the mean-lithosphere frame, the net-rotation angular velocity $\omega_{\mathrm{nr}}$ is subtracted from the angular velocity $\omega_{p}$. The mean-lithosphere framework is a reference frame based on the global plate geometry and velocities of every plate. Thus, any change in the assumed relative plate velocities and geometry results in a different net-rotation of the lithosphere. Indeed, using various plate motion models, hotspot locations or geometrical factors yield different values of net-rotation angular velocity: $0.251^{\circ} \mathrm{Myr}^{-1}$ about a pole located at $51.50^{\circ} \mathrm{S}, \quad 65.60^{\circ} \mathrm{E}$ (Harper, 1986); $0.150^{\circ} \mathrm{Myr}^{-1}$ about a pole located at $56.00^{\circ} \mathrm{S}, 84.00^{\circ} \mathrm{E}$ (Ricard et al., 1991); $0.33^{\circ} \mathrm{Myr}^{-1}$ about a pole located at $49.20^{\circ} \mathrm{S}, 64.90^{\circ} \mathrm{E}$ (Argus and Gordon, 1991); $0.436^{\circ} \mathrm{Myr}^{-1}$ about a pole located at $55.91^{\circ} \mathrm{S}, 69.93^{\circ} \mathrm{E}$ (Gripp and Gordon, 2002). Although unresolved questions about hotspots remain, such as the number and the source depth (Foulger et al., 2005), nonetheless the hotspot reference frame remains a convenient - and easy to visualize - framework in which to study plate kinematics and dynamics. Thus we utilize the hotspot framework in our study.

\section{Discussion}

We have estimated current velocities for the plates including 38 new microplates in the hotspot reference frame, incorporating the PB2002 model (Bird, 2003). We also present a new net-rotation angular velocity including microplate contributions and necessary rotation to obtain plate angular velocities in the mean-lithosphere framework. Our results (Table 1, Figs 2-5) show some kinematic and geometric patterns related to plate size. No continuum or gradational distribution of plate size exists. Plates clearly partition into three groups: large, middle and small. The seven large plates (PA, AF, AN, NA, EU, AU, SA) all exceed $1.03 \mathrm{sr}$; together these comprise $81.0 \%$ of the Earth's surface and dominate with $85.3 \%$ of the net-rotation velocity computation. Next, the seven middle plates (SO, NZ, IN, SU, PS, AM, $\mathrm{AR}$ ), in the range of $0.47-0.12 \mathrm{sr}$, cover $14.0 \%$ of the surface area and contribute $9.8 \%$ of the velocity computation. The remaining 38 plates span three orders of magnitude in size and lie in the range $0.0748-0.0002 \mathrm{sr}$, accounting for $4.9 \%$ of the total area and $5.2 \%$ of the total net-rotation.

The distribution of the plates over Earth's surface shows a relation to the size-grouping of plates. The large-

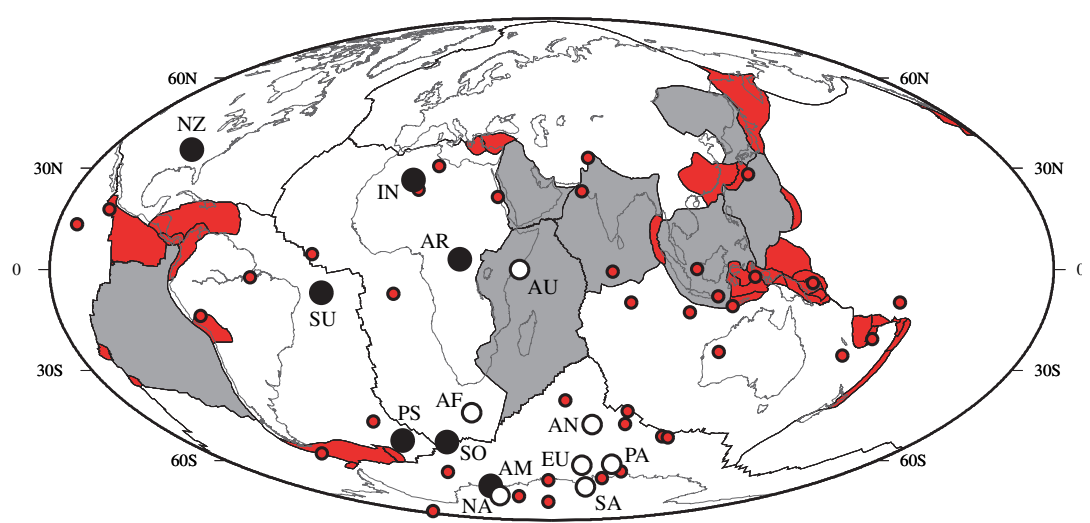

Fig. 2 Large (white), middle (grey) and small (red) plates and respective rotation poles, open, black and red circles.

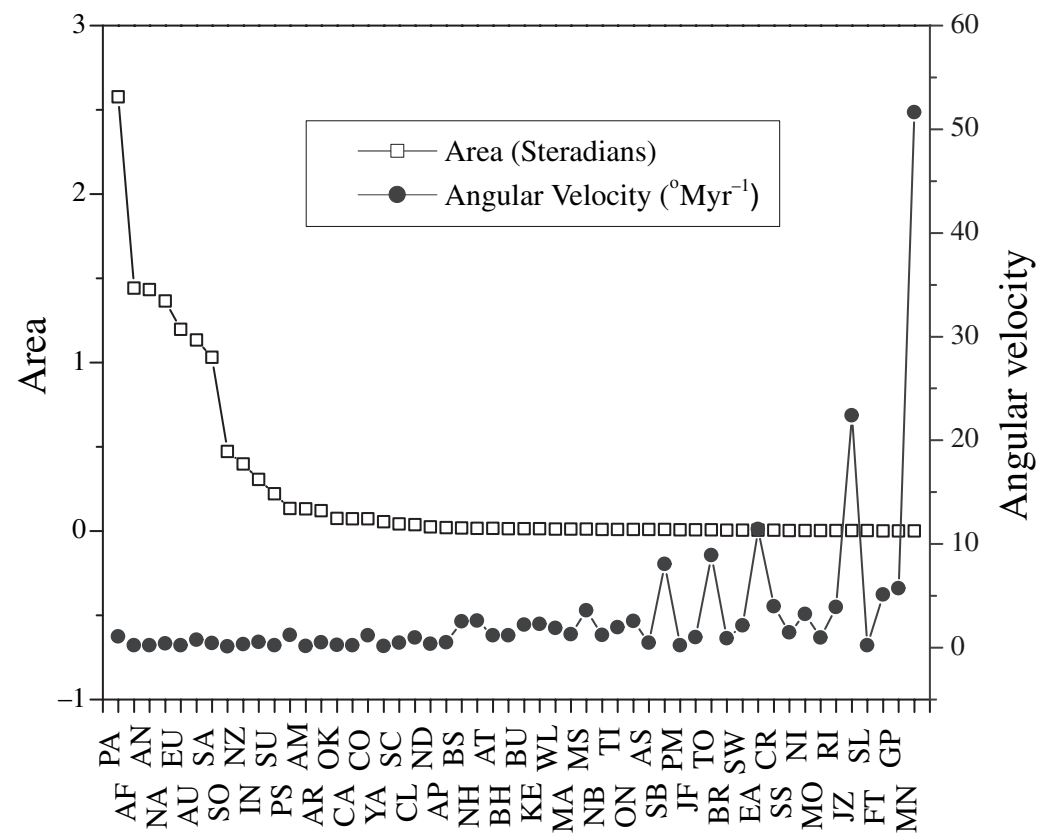

Fig. 3 Microplates and plates (sorted by area) vs. plate area (left axis) and angular velocities relative to the hotspots (right axis). sized lithospheric plates cover most of the Earth's surface. Middle-sized plates are positioned in equatorial regions (except AM, Fig. 2), whereas most of the small plates lie on the interfaces of the large plates, i.e. the Australia-Pacific, the Eurasia-Pacific and the Nazca-South America boundary (Fig. 2), suggesting that some might be interpreted as parts of the diffuse margin of the two large plates. In addition, the plate angular velocities show a pattern with plate size: these generally increase with decreasing plate area (Fig. 3) reaching the 

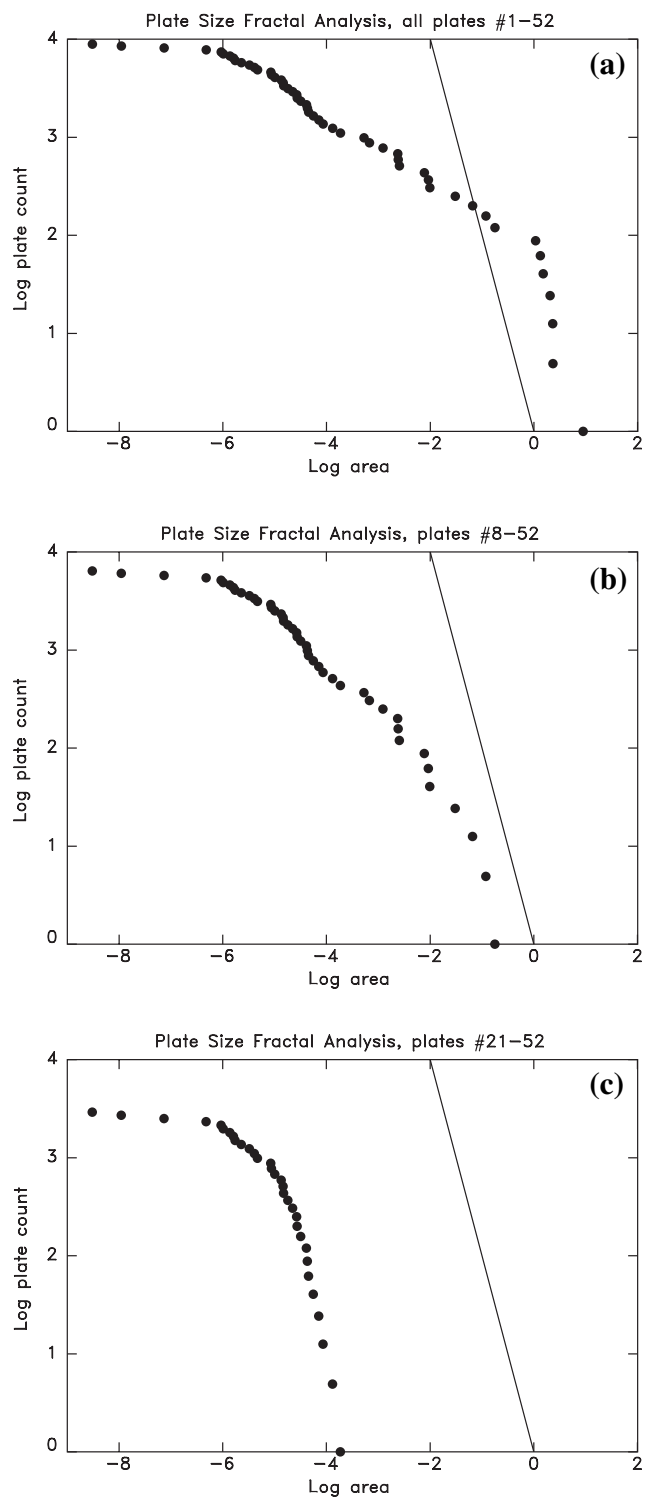

Fig. 4 Log of plate count vs. the log of the plate area in steradians. The 52 plates have non-fractal behaviour. The largest seven plates show one slope (a), wheareas the remaining plates show another, (b) for middle plates, (c) for the remaining microplates. Reference line has a slope of -2 .

highest values for some of the smallest plates (e.g. JZ and MN).

Fractals relate geometry at different scales, and as Feder (1988) argues, can give insight into our understanding of naturally occurring objects. The plates, which range in size over four orders of magnitude (Table 1), provide a compelling opportunity for fractal analysis. We examine the fractal behaviour of the plates by plotting the log of the plate area in steradians vs. the log of plate count (shown in Fig. 4). Bird has considered the fractal properties of the plates (Bird, 2003, his Fig. 19) and finds that the plates having areas between 0.002 and $1.000 \mathrm{sr}$ (JZ to SA for his 38 plates) can be approximately described by a power law:

$$
\mathrm{Cc} \approx 7 A^{-1 / 3}
$$

where $\mathrm{Cc}$ is the cumulative count of plates and $A$ is the plate area in steradians.

Here, we note that the fractal behaviour of the plates also depends on the size range. In Fig. 4, we show that the largest seven plates define one slope, or fractal behaviour, and the middle seven another slope, whereas remaining 38 plates have a different fractal behaviour. The largest seven (omitting the Pacific as an exception, as Bird has done) have a slope of less than -2 (Fig. 4a). The middle-sized plates (Fig. 4b) have a slope of less than -2 (the reference line), and the small plates - particularly no. 22-48 match the reference line slope of -2 (Fig. 4c). The change in slope from -2 may be a consequence of a clustering behaviour for the smaller plates. This clustering ceases once the plate's size increases from about $4 \%$ to more than $12 \%$ of the surface of the Earth. Feder (1988) shows a similar fractal behaviour for the clustering of silica particles (e.g. Feder, 1988, Chapter 3). The curve flattens for the smallest plates. Bird's explanation for this flattening of the curve lies in the current incompleteness of the data set for plates smaller than SL, 0.0002 sr.

Additional patterns emerge concerning the absolute motions of the plates based on their groupings by size. The Euler poles for large plates concentrate over less than $10 \%$ of a hemisphere near a mean latitude of $60^{\circ} \mathrm{S}$, except for $\mathrm{AU}$, a consequence of its north-west motion (Fig. 5a). However, the Euler poles for middle-sized plates are generally more equatorial in distribution, but scatter more, spread over about $20 \%$ of a hemisphere (Fig. 5a). The rotation poles of the small plates generally show considerable scatter, although poles avoid the regions populated by the poles for the large and middle-sized plates (Fig. 5b). This is a consequence of microplate behaviour, as noted by Engeln et al. (1998): the rotation poles describing microplate motion lie close by, thus have large rotations. This may explain the difference in location of rotation poles and size of the rotation for small microplates, when compared with the seven larger plates. These high velocities and the locations of rotation poles fairly close to the corresponding plates may offer a criterion to distinguish independent microplates from diffuse margins.

We have shown in this paper that there appears to be a natural partitioning of plates into three groups based on their size. Each subset of plates shares some common charac- 

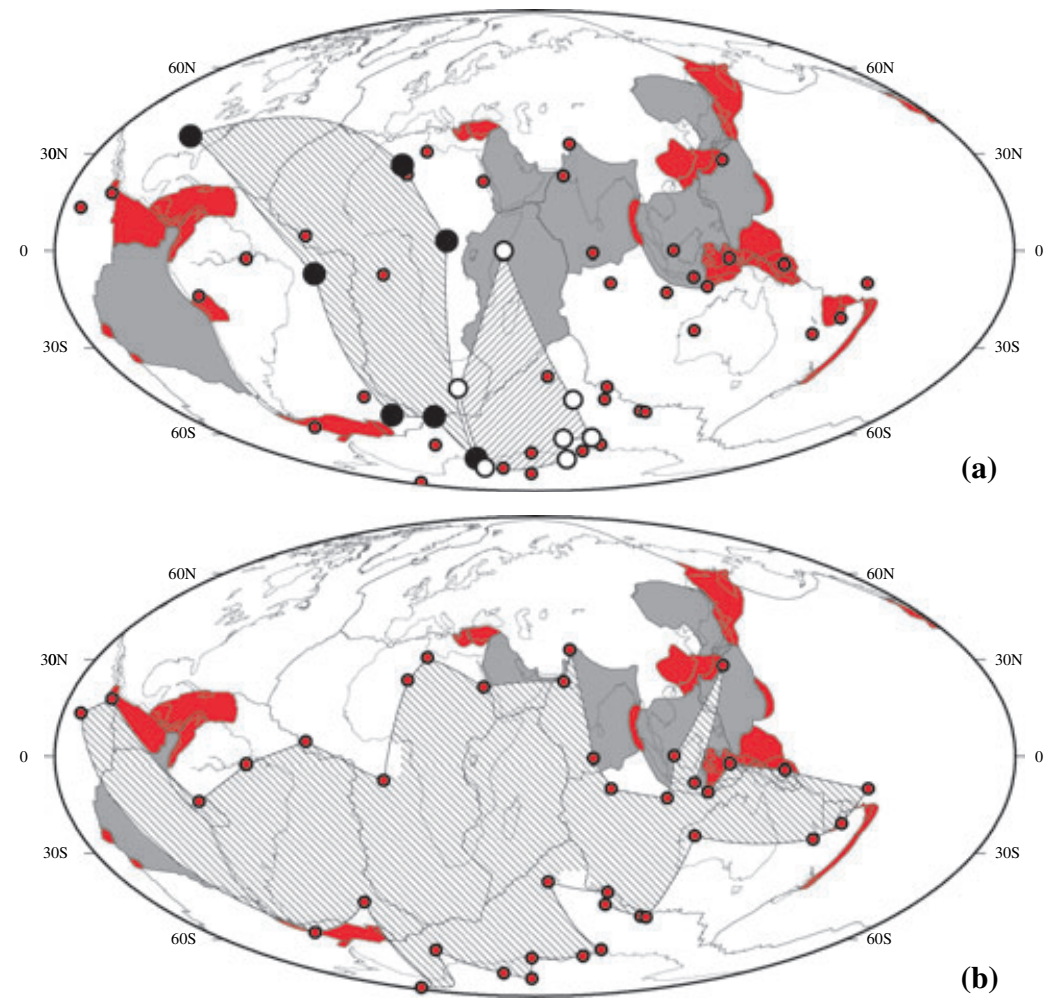

Fig. 5 (a) The Euler poles for large plates concentrate over les that $10 \%$ of a hemisphere near a mean latitude of $60^{\circ} \mathrm{S}$, except for AU. However, the Euler poles for middle-sized plates are generally more equatorial in distribution, and these scatter more, about $20 \%$ of a hemisphere. (b) The rotation poles of the small plates generally show considerable scatter, although poles avoid the regions populated by the poles for the large and most of middle-sized plates.

teristics. These similarities within groups include the nature of plate distribution over the Earth, location of rotation poles, size of the corresponding rotations, as well as the observed fractal behaviour. This breakdown by plate size may be a natural consequence of plate tectonics: large plates and most of the middle being moved predominantly by driving forces, and small ones clustering at the interfaces.

\section{Acknowledgements}

We are grateful to Michael Stefanick for discussion and insights into fractal analysis and to Seth Stein for his careful reading of the manuscript and apt comments. Also, we thank Peter Bird for the plate boundary
DeMets, C., Gordon, R.G., Argus, D.F. and Stein, S., 1994. Effect of recent revisions to the geomagnetic reversal time scale on estimates of current plate motions. Geophys. Res. Lett., 21 , 2121-2194.

Engeln, J.F., Stein, S., Werner, S. and Gordon, R.G., 1998. Microplate and shear zone models for oceanic spreading center reorganizations. J. Geophys. Res., 93, 2839-2856.

Feder, J., 1988. Fractals. Plenum Press, New York.

Forsyth, D.W. and Uyeda, S., 1975. On the relative importance of the driving forces of plate motion. Geophys. J. Roy. Astron. Soc., 43, 163-200.

Foulger, G.R., Natland, J.H., Presnall, D.C. and Anderson, D.L., 2005. Plates, plumes, and paradigms. Geol. Soc. Am. Spec. Pap., 388, 861pp.

Gordon, R.G. and Jurdy, D.M., 1986. Cenozoic global plate motions. J. Geophys. Res., 91, 12384-12406.

Gripp, A.E. and Gordon, R.G., 2002. Young tracks of hotspots and current plate velocities. Geophys. J. Int., 150, 321-364.

Harper, J.F., 1986. Mantle flow and plate motions. Geophys. J. Roy. Astron. Soc., 87, 155-171.

Jurdy, D.M., 1990. Reference frames for plate tectonics and uncertainties. Tectonophysics, 182, 373-382.

Lliboutry, L., 1974. Plate movement relative to a rigid lower mantle. Nature, $\mathbf{2 5 0}$, 298-300.

Morgan, W.J., 1972. Plate motions and deep mantle convection. Studies in Earth and Space Sciences, Geol. Soc. Am. Mem., 132, 7-22.

Ricard, Y., Doglioni, C. and Sabadini, C., 1991. Differential rotation between lithosphere and mantle: a consequence of lateral viscosity variations. J. Geophys. Res., 96, 8407-8415.

Solomon, S. and Sleep, N.H., 1974. Some simple physical models for absolute plate motions. J. Geophys. Res., 79, 25572567.

Wessel, P. and Smith, W.H.F., 1995. New version of generic mapping tools released. EOS Trans. Am. Geophys. Union, 76, 329.

Wilson, J.T., 1973. Mantle plumes and plate motions. Tectonophysics, 19, 149164.

Received 23 February 2006; revised version accepted 31 May 2006 